\title{
Obstrucción intestinal por Ascaris Lumbricoides
}

Intestinal Obstruction by Ascaris Lumbricoides

*Gerardo José Ayestas Moreno.

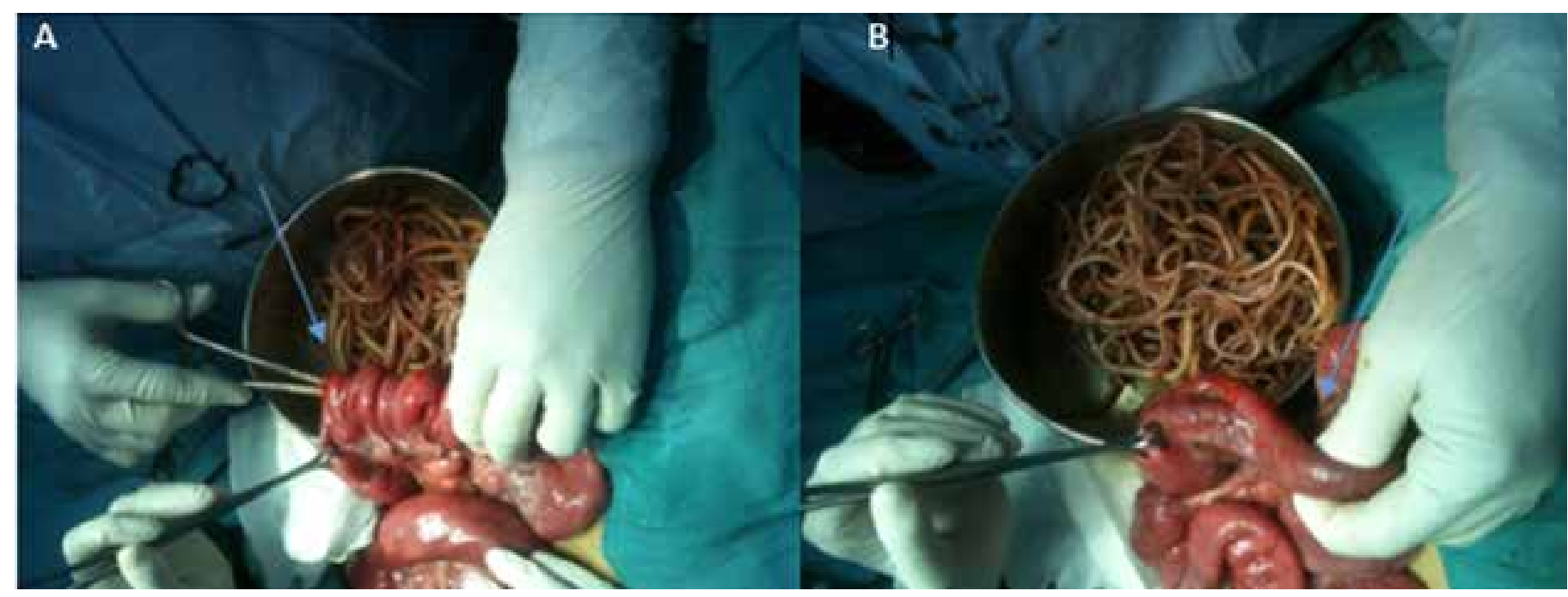

Figura 1. A: Se observa duodeno con enterotomia, de donde se realizo extracción instrumental de Áscaris Lumbricoides. B. Se realiza palpación manual para valorar permeabilidad intestinal.

Paciente femenina de 8 años de edad, llega a emergencia del Hospital de area del departamento de Lempira, con dolor abdomial de 2 dias, tipo colico, moderado, acompañado de vomitos y paro de evacuaciones de igual tiempo. Al examen físico paciente de bajo peso, con desnutrición proteico calórica crónica, se palpa masa abdomial localizada en hipogastrio, dolorosa, movil. Al tacto rectal: ampolla rectal vacía. Se realiza laparotomia exploratoria Enterotomia por obstruccion mecanica, encontrandose Ascaris Lumbricoides en luz intestinal, extrayendose incontable cantidad, no se encontraron lesiones 0 necrosis intestinal.

La infección intestinal por Ascaris Lumbricoides puede producir daño mecánico por obstrucción del lumen intestinal, alteración de perfusión, perforación de la pared y peritonitis. El riesgo de oclusión intestinal es mayor en niños pequeños y está relacionado con el número de parásitos, ${ }^{(1)}$ La suboclusion puede ser tratada medicamente con precaución, pero en la oclusión intestinal el tratamiento médico no es recomendable, por riesgo a migración larvaria, pero al presentarse signos y síntomas de abdomen agudo la laparotomía exploradora de urgencia es indicada. ${ }^{(2)}$

\section{REFERENCIAS BIBLIOGRÁFICAS.}

1. Orso P, Cantou. Ascaris lumbricoides Complicaciones graves en niños hospitalizados en el Centro Hospitalario Pereira Rossell. Archivo de pediatría del Uruguay. 2014; 85(3): 149-154.

2. Moscatellia, Orbe G. Ascariasis intestinal. Archivo argentino de pediatría. 2015; 113 (6):4-9. 